\title{
El Continente Americano dentro de la Problemática Mundial*
}

\begin{abstract}
José AUguSTo DE ARAÚJo CASTRo, embajador, diplomático de carrera e intelectual brasileño, representa a su país ante el gobierno de los Estados Unidos. Fue Ministro de Relaciones Exteriores del Brasil de 1963 a 1964. Posteriormente, fue Embajador en Atenas y en Lima, y Jefe de la Misión del Brasil ante las Naciones Unidas entre 1968 y 1971. Mientras desempeñaba este cargo, pronunció la conferencia en que se basa este artículo.
\end{abstract}

El mundo político no hace sino complicarse, pero eso no significa necesariamente que estemos más próximos de la guerra de lo que estábamos en la última quincena de octubre de 1962, fecha importante que no podrá ser despreciada ni ignorada en cualquier estudio más detenido y acucioso de la situación internacional. Porque, a partir de ese momento, esto es, a partir de los "trece días" de crisis, provocada por la colocación de mísiles soviéticos en Cuba, se inició una fase de entendimientos y contactos diplomáticos permanentes entre la Unión Soviética y los Estados Unidos de América. En otras palabras, con las vicisitudes inevitables en todo complejo de hechos políticos y diplomáticos, se inició un proceso que, con el correr del tiempo, fue siendo caracterizado como de détente, o de relajamiento de las tensiones internacionales.

No cesó todavía -y no cesará en un futuro inmediato y previsible- la confrontación político-militar entre los Estados Unidos de América y la Unión de Repúblicas Socialistas Soviéticas. Como ya tuvimos oportunidad de decir, el juego continúa, pero las reglas del juego cambiaron de manera sustancial. No es probable que la confrontación que persiste sea enteramente superada por un periodo de negociación. Lo probable es que subsistan, simultánea y paralelamente, la confrontación y la negociación, tal como está sucediendo hoy en varias áreas, especialmente en la del Medio Oriente. Los acuerdos tácticos que están siendo alcanzados por los Estados Uni-

* Basado en una conferencia del Representante Permanente de Brasil en la ONU, Embajador J. A. de Araújo Castro, pronunciada en el Colegio Interamericano de Defensa el 11 de diciembre de 1970, en Washington, D. C. 
dos de América y la Unión Soviética no representan más que "acuerdos de supervivencia". La supervivencia es, evidentemente, el primer requisito de la confrontación:

\section{LA PAZ Y LA DÉTENTE}

A partir de octubre de 1962, pareció existir -y esa impresión debería confirmarse en agosto de 1968- un cierto entendimiento tácito entre las dos superpotencias, en el sentido de evitar la exacerbación de las crisis y tensiones en determinadas áreas, consideradas de interés especial para una u otra de las superpotencias.

Es de notar que, si fueron muchos los que censuraron la invasión de Checoslovaquia, fueron relativamente pocos $-\mathrm{y}$ no necesariamente los más poderosos- los que condenaron la peligrosa doctrina. de la "soberanía limitada" en la que ella se apoyaba. Ahora bien, una invasión, como episodio, tal vez sea menos peligrosa que una doctrina, como norma política, responsable de las ideas y conceptos de esferas de intereses y de áreas de influencia, susceptibles de transformarse en áreas de dominación.

Tuvimos la oportuniddd de ser testigos de hechos y circunstancias, sobre ese particular, debido a la responsabilidad que nos cabía, en agosto de 1968, de presidir las Sesiones del Consejo de Seguridad. Era tan fuerte el interés recíproco de las dos superpotencias en la preservación del espíritu de la détente, que se reveló capaz de resistir a todo: al conflicto de Vietnam, a la invasión de Checoslovaquia y también a la confrontación en el área político-estratégica del Medio Oriente.

Las superpotencias parecen determinadas a evitar la eclosión de un conflicto mundial, con tonalidades nucleares, pero al mismo tiempo parecen no tener esperanza en la paz universal, de la misma manera que parecen haber perdido la esperanza en el desarme general y completo.

Una détente no es la paz, es apenas un proceso de relajamiento de tensiones, fundado en la simultaneidad de confrontación y negociación. Para las superpotencias, la paz significa, pura y simplemente, la no eclosión de un conflicto nuclear. En ese sentido restringido es que podemos decir que las Naciones Unidas consiguieron preservar la paz en estos veinticinco años que nos separan de su creación. Para las potencias mayores, en la medida en que se diferencian de las superpotencias, la paz es un estado tolerable de tensiones que no determinan las necesidades de una movilización militar o económica de dimensiones nacionales. 
Para los países más pequeños, la paz tiende a identificarse con la seguridad; esto es, con la soberanía política, la inmunidad de agresión, la no intervención y la integridad territorial. Es claro que los países medios y pequeños no pueden adoptar conceptos demasiados sofisticados en materia de paz y seguridad.

Por la fuerza de sus responsabilidades mundiales, las superpotencias están, de este modo, obligadas a aceptar el concepto de paz como "un estado tolerable de conflicto" y a aceptar el desarme como "un grado tolerable de la carrera armamentista". Obsérvese, de un lado, la situación en el Medio Oriente, donde se piensa en términos de "cese del fuego" antes que en una solución política permanente $y$, de otro lado, piénsese en las conversaciones sobre limitación de armamentos (SAIT); conducidas intermitentemente en Viena 'o en Helsinki, en las cuales se busca apenas una eliminación de lo superfluo y del excedente en materia de armas nucleares estratégicas. Las conversaciones SALT no contemplan, en la realidad, sino la eliminación del over-overkill, con la premisa básica de que las dos superpotencias conversarían, al menos en esta etapa preliminar, su capacidad de overkill.

EL PANORAMA VISTO DESDE 1947: CONTENCIÓN Y CONFRONTACIÓN

Todas esas circunstancias, perfectamente identificables en el proceso de détente, vinieron evidentemente a modificar en su totalidad el panorama internacional, en relación al que prevalecía en los años de 1947 y 1949, cuando se forjaron las doctrinas, las teorías y los instrumentos de la gran alianza occidental.

La fase de confrontación entre Ios EE.UU. y la URSS se inició en la serie de decisiones fundamentales adoptadas por el Presidente Truman en la primavera de 1947, en respuesta a la amenaza comunista contra Grecia y Turquía. La doctrina Truman, el plan Marshall y más tarde la Alianza del Atlántico Norte (OTAN) son aspectos diferentes de la estrategia de contención del comunismo en Europa Occidental y regiones adyacentes, enunciada en el artículo firmado por " $\mathrm{X}$ " - George Kennan - en la revista Foreign Affairs de julio de 1947.

Se acepta, generalmente, que los principios de la estrategia de contención estaban escritos en el pasaje más famoso y más citado del mensaje del Presidente Truman al congreso norteamericano con respecto a la asistencia a Grecia y a Turquía, como sigue:

"Creo que debe ser política de los EE.UU. apoyar a los pueblos 
libres, que están resistiendo las tentativas de subyugación por minorías armadas o por presiones externas".

"Creo que debemos ayudar a los pueblos libres a alcanzar su propio destino, por sus propios caminos".

Aunque el Presidente Truman se estuviese refiriendo sólo a los problemas griego y turco, su formulación es genérica y permite identificar la vocación mundial que informó la estrategia norteamericana.

De otros aspectos del mensaje presidencial deben ser destacados su unilateralidad, que implicó el reconocimiento de la impotencia del mecanismo de seguridad colectiva consagrado en la Carta de las Naciones Unidas, y la invocación de lo que más tarde se vería apellidado como "teoría del dominó".

La doctrina Truman acogió también la premisa de que la Unión Soviética estaba empeñada en una política de agresión ideológica y militar que amenazaba a toda Europa Occidental y al Medio Oriente. En esas condiciones, como teoría de política exterior, más tarde abandonó el énfasis meramente territorial, esto es, de mantenimiento de posiciones estratégicas de Occidente en Grecia y. Turquía, lazos vitales en la línea de comunicaciones que pasa por el Mediterráneo Oriental, para transformarse en una estrategia global de contención ideológica y militar del comunismo.

A pesar de estar formulada en términos defensivos, la estrategia de contención tuvo también alguna preocupación ofensiva, especialmente en los años en que John Foster Dulles dirigió la política externa norteamericana (EI propio diccionario Webster define la palabra "containment" como correspondiendo "específicamente a la política de tratar de evitar que se esparza la influencia de una nación o sistema político enemigo"). A propósito, vale la pena citar las constantes afirmaciones, efectuadas durante el gobierno de Eisenhower, de que el objetivo de EE.UU. en Europa Oriental, era hacer retroceder al comunismo ("rollback").

La política de contención sirvió, durante casi veinte años, de telón de fondo para el consenso bipartidario, internacionalista (en contraposición al aislacionista, que prevaleció en el período entre las dos guerras mundiales), con relación de los objetivos y métodos de la política externa norteamericana. La ruptura de ese consenso, resultante de la participación de los EE.UU. en las hostilidades de Vietnam, se reviste de una importancia que difícilmente puede ser exagerada.

La política de contención, que se basaba en un último análisis en la premisa de que el monopolio nuclear norteamericano sería mantenido, siempre muy relacionado con los objetivos y preocupaciones estratégicas de los EE.UU. durante la guerra fría, los cuales 
trascendian la mera seguridad física del territorio de los EE.UU. en el sentido estricto, y se encaminaban al establecimiento de un orden internacional no sólo contrario al comunismo sino también propicio al liberalismo económico y al sistema de gobierno democrático al estilo americano; a la adopción, por los demás países de Ia experiencia de los EE.UU. como modelo de desarrollo político y económico, y a la garantía de las inversiones norteamericanas en el exterior.

La práctica diplomática y militar norteamericana chocó con el dinamismo $y$.la tendencia a la expansión del comunismo y con los sistemas defensivos soviéticos, heredados de la historia rusa y reforzados por las experiencias de la guerra civil y de la invasión hitlerista. Varios factores contribuyeron para aumentar el temor y la desconfianza de los soviéticos: por ejemplo, el monopolio nuclear norteamericano en la primera fase de la guerra fría; la clara preponderancia política, económica y militar de los EE.UU., tanto de Europa Occidental cuanto de Japón (al fin de la segunda guerra, un general americano estaba instalado en Berlín, y otro en Tokio); y la aplicación gradual de la estrategia de contención en todo el mundo no comunista y no sólo en Europa Occidental y las áreas vecinas.

El universalismo o globalismo de los EE.UU. se contrapone a la orientación soviética, preocupada ostensiblemente con una política de esferas de influencia en Europa Oriental. Unicamente, convendría resaltar que el universalismo norteamericano era visto por los EE.UU. como intervencionista y agresivo, como declaración virtual de que todo el mundo, fuera de las fronteras de los países socialistas, estaba incluido en la esfera de influencia de los EE.UU. Estos, por su lado, tenderán siempre a entender la política soviética en Europa Oriental como el primer paso de una estrategia universalista para la conquista de Europa Occidental y, subsiguientemente, del resto del mundo. Los padrones de referencia de los EE.UU. y de la URSS no contribuian, por consiguiente, a la disminución de la tensión entre los dos países.

el Neutralismo, una Víctima de la dÉtente

El establecimiento de contactos diplomáticos permanentes entre los Estados Unidos de América y la Unión Soviética hizo disminuir, de manera significativa, la influencia del llamado bloque neutralista o no alineado. Ese bloque, formado bajo la égida de la India, de la República Arabe Unida y de Yugoslavia, nunca pudo aspirar al 
papel de una tercera fuerza en el jlano político. Se trataba, antes, de una fuerza diplomática, puramente política, capaz en ciertos casos, de realizar una tentativa de mediación entre los países occidentales y los países del mundo socialista.

Entretanto, a medida que los dos polos se tornaban menos rígidos, el eje intermedio de los no alineados comenzó a vacilar y a debilitarse. No existen hoy intermediarios en las relaciones diplomáticas entre los EE.UU. y la URSS. Los contactos son estrechos, directos y permanentes, no obstante la persistencia de la confrontación de poder. Hoy nadie habla de "tercera fuerza". Se habla de "tercer mundo".

\section{LOS CO-PRESIDENTES - $Y$ LOS MEDIADORES}

Ya se ha visto lo que aconteció en el ámbito de la Conferencia del Comité sobre el Desarme, o con más propiedad, en el ámbito del antiguo Comité de Dieciocho Naciones para el Desarme. Cuando el Comité se instaló en Ginebra, el 15 de marzo de 1962, estaba integrado por cinco miembros del bloque occidental (tal vez fuese más preciso decir cuatro miembros, ya que Francia nunca participó de los trabajos del Comité); de cinco miembros del Pacto de Varsovia, y de ocho miembros mediadores (Brasil, Birmania, Etiopía, India, México, Nigeria, República Árabe Unida y Suecia). La presunción generalizada era que esos países tenían la función de aproximar diplomáticamente a los dos lados antagónicos, en el ejercicio de una función diplomática de mediación.

Tal vez la realidad haya cambiado, o tal vez los ocho países mediadores hayan tenido demasiado éxito en sus esfuerzos diplomáticos, pues lo que aconteció, para sorpresa generalizada, fue que bajo la égida de dos Co-Presidentes, los dos lados antagónicos casi se reconciliaron y, como sucedió en el caso del Tratado de No Proliferación Nuclear, comenzaron a desarmar a los ocho mediadores, que ahora son doce, con la ampliación del Comité de Ginebra.

Toda la negociación del Tratado de No Proliferación, como también del Tratado de Desnuclearización del Fondo del Mar, revelo un alineamiento inesperado: de un lado, los Co-Presidentes al frente de sus aliados de la OTAN y del Pacto de Varsovia; del otro, los países que se designaban como mediadores, neutralistas o no-alineados. Por eso mismo, la designación de no alineados a que taimadamente se aferró el grupo de países que últimamente se reunió en Dar-es-Selain y en Susoka, representaba un remanente de la Guerra Fría y era un anácronismo semạntico que debía ser corre- 
gido. La co-presidencia adoptada en Ginebra se tornó, así, en un modelo y en un símbolo de una nueva modalidad política y de un nuevo arte: el arte de co-chairmanship, a cargo de las dos superpotencias.

\section{CONVERSIÓN SEMÁNTICA DE DULLES}

Es de interés observar la aparición de ciertas mutaciones políticas y semánticas. En los años de la guerra fría, en el tiempo de Foster Dulles, los americanos revelaban mayor desconfianza que los soviéticos en relación con los no-alineados y neutralistas; hoy son los rusos quienes están más cercanos a la teoría "quien no está conmigo, está contra mí". En cuanto la política americana se tornó más tolerante, más dúctil, más flexible y más sofisticada, con la introducción del concepto de "diplomacia total", los soviéticos, por un proceso de reversión, comenzaron a defender tesis que eran extremadamente agradables a los oídos de Foster Dulles. Citaremos, como ejemplo, la idea del establecimiento de un sistema de "seguridad colectiva en el Asia", y un énfasis obsesivo en los "sistemas regionales de seguridad". Con el correr del tiempo, la guerra fría empezó a desarrollarse en favor de los intereses de los Estados Unidos de América y la Unión Soviética empezó a tomar posiciones cada vez más defensivas.

La verdad es que después de casi dos décadas de vigencia, el esquema conceptual en que se basaba la confrontación indiscriminada comenzó a declinar. Én la práctica, las relaciones EE.UU. - URSS desembocaron en una impasse, cuya superación, en los límites de aquel esquema, sólo podría ser alcanzada con costos políticos y militares excesivos o inaceptables.

Factores extrínsecos e intrínsecos de la política externa de los EE.UU. contribuyeron a tal declinación. Entre los primeros, figuran el fin del monolitismo del bloque socialista; en la medida en que expresiones como "bloque socialista" y "comunismo internacional". pierden su poder para describir acertadamente la realidad - por faltar al bloque socialista, hoy, unidad de doctrina y de ejecución política-, ha sonado la hora de revisar los modelos de confrontación y de contención.

Otro factor extrínseco es el surgimiento, entre los países del mundo no comunista, de subcentros de poder, como Francia, Alemania y Japón, que tienden a adoptar, en defensa de sus intereses regionales, posiciones propias y no necesariamente coincidentes con las norteamericanas. Esos fraccionamientos, en Oriente y Occidente, contribuirán a atenuar el bipolarismo que prevaleció en la primera 
fase de la posguerra y para tomar más difícil a los EE.UU. y la URSS el traducir su hegemonía militar y política en actos concretos.

Un tercer aspecto, no menos importante, sería el establecimiento gradual de un "equilibrio del terror". Dada la flaqueza relativa de la URSS al fin de la Gran Guerra y su incapacidad de actuar fuera de las regiones que le son adyacentes, es comprensible que la estrategia de confrontación pudiese haber sido imaginada especialmente en términos de contención regional estricta. Vencida esta fase, la confrontación EE.UU. - URSS se globalizó, lo que terminó por vaciar el esquema conceptual de contención (que se mostró menos eficiente en el plano mundial de lo que había sido en el regional).

Entre los factores intrínsecos, mencionaría dos principales: la política de los EE.UU. en Vietnam, y la impasse a que llegó la carrera armamentista nuclear. El Vietnam probó que hay límites más allá de los cuales la estrategia de contención desatiende ciertos objetivos vitales de la sociedad norteamericana. Esa circunstancia fue tal vez uno de los factores que llevaron al gobierno de Nixon a repensar la posición estratégica de los EE.UU. y a lanzar el "slogan" de que "estamos iniciando una era de negociaciones".

En el campo de la guerra limitada, con armamentos convencionales, son crecientes los obstáculos de todo orden a la participación directa, sea de los EE.UU. o de la URSS, conforme demuestran las actuales hostilidades en Vietnam. En primer lugar, hay factores políticos, militares y tecnológicos que conspiran contra el mantenimiento de carácter limitado de las guerras "locales". En segundo lugar, se va percibiendo que en Vietnam, por ejemplo, un poder convencional teóricamente incontrastable está siendo enfrentado, bien o mal, por tácticas de guerrillas. En tercer lugar, la participación de una de las superpotencias en un conflicto limitado atrae, casi inexorablemente, la participación de otra, aunque en forma indirecta. Finalmente, la propia extensión territorial del Tercer Mundo, teatro probable de guerras limitadas, desanima la dispersión de hombres, armas y equipos en áreas de fricción, muchas veces con remota impotencia política para las superpotencias.

El segundo factor intrínseco es la percepción de que son crecientes los costos financieros y sociales de investigación y desarrollo de nuevos armamentos nucleares, y de sistemas de detección y de transporte (mísiles). La carrera armamentista entre las dos superpotencias llegó claramente a un "plateau", el cual sólo sería superado, por la vía de la confrontación, si fueren realizadas inversiones astronómicas en artefactos extremadamente sofisticados, de los cuales los MIRV y los ABM serían meros precursores.

El equilibrio de poder entre los EE.UU. y la URSS fue alcanzado en términos de terror y de "overkill" y la racionalidad funcional 
del sistema fue expresada por una ecuación de poder en que cualquiera de los contendientes tiene teóricamente la capacidad de sobrevivir a un ataque masivo desplegado por sorpresa por el otro $y$, en seguida, de replicar de manera devastadora.

La aceleración de la competencia de armamentos implicaría un aumento exponencial de los esfuerzos hechos hasta ahora, con inesperadas repercusiones económicas y sociales. Después de eso, podría destruir el actual equilibrio nuclear. Como consecuencia de esos hechos inseparables, y de ciertas acomodaciones políticas en otras áreas, los EE.UU. y la URSS decidieron, por ejemplo, reunirse en conversaciones intermitentes para la limitación de elementos estratégicos (SALT).

La obsolescencia del modelo de contención se viene arrastrando desde hace varios años. Los Presidentes Kennedy y Johnson, apenas en el poder, tomaron conocimiento de esa degeneración. El último, con todo, vio su capacidad de proponer un nuevo diagnóstico y ejecutar la correspondiente terapéutica, severamente limitada por la controversia en torno al compromiso de los EE.UU. en Vietnam, el cual fue justificado, en gran parte, por el propio esquema de contención del comunismo aplicado en Asia.

El modelo de contención y de confrontación daba señales de haber perdido relevancia, de haber disminuido su capacidad de explicar hechos nuevos, y de haber descendido de los altos niveles alcanzados en la fase más aguda de la guerra fría, en términos de rigor, de capacidad de predicción, de posibilidades de combinación y de riqueza heurística

A pesar de todo eso, el modelo de contención y de confrontación retenía y todavía retiene ciertas ventajas. Se trata de un modelo simple, económico, global y de fácil comprensión, que establece una línea clara entre aliados y adversarios que ya ganó títulos de tradición y se transformó en un hábito o en una actitud mental. Finalmente, al postular la irreductibilidad de aliados y adversarios, la política de contención sirve de argumento poderoso para mantenér alineados a los primeros, pues cualquier disensión favorecería por hipótesis, a los últimos.

El certificado de defunción de las bases intelectuales de la política de contención global fue extendido, tal vez, por el propio arquitecto de la contención, en sentido estricto, George Kennan, en su libro de memorias:

"La quiebra (de la contención) consistía en el hecho de que nuestro propio gobierno, considerando difícil entender una amenaza política como tal y enfrentarla por medios no militares, estaba seriamente engañado, en particular, por su propia interpretación errónea de la guerra de Corea, y dejó de aprovechar 
las oportunidades para una disensión política provechosa, en los años que siguieron, y se esforzó, de acuerdo con sus preocupaciones militares, en construir y perpetuar la división de Europa, cuya eliminación debería haber sido su objetivo. No fue la "contención" que falló, fueron sus resultados que nunca se materializaron.

\section{IDEOLOGÍA DEL PODER}

En realidad, la Unión Soviética tiende cada día a afirmarse menos como factor de agitación revolucionaria (sector hoy reservado a China y Cuba) que, como gran potencia que ha llegado tarde al club de las grandes potencias, tampoco actúa siempre con mucha discreción y sutileza. La URSS se afirma militar y politicamente en muchas áreas geográficas que anteriormente le parecieron vedadas. Nunca los rusos -y ya no decimos los soviéticos- circularon utilizando medios políticos y militares ortodoxos con tanta desenvoltura en el Mediterráneo, en el Medio Oriente y en África del Norte.

El comunismo como doctrina está en crisis y se diversifica en varias sectas y herejías, pero la URSS crece como estado, si no necesariamente como imperio. La Unión Soviética realiza un gran esfuerzo para obtener un cierto grado de respetabilidad diplomática y el reciente Tratado de No Agresión, firmado con Alemania Occidental, facilitará mucho su penetración política, ya que no ideológica, en Europa Central. La détente está conduciendo a la Unión Soviética hacia el centro de la escena política mundial.

Está claro que la infiltración política e ideológica opera en ambos sentidos y, en el cuadro europeo, el mundo socialista puede ser aún más vulnerable a las ideas occidentales que el Occidente a las ideas. comunistas.

Debe pensarse que fueron la influencia industrial y comercial, y la posibilidad de mayor penetración alemana en Checoslovaquia, las que contribuyeron poderosamente a llevar a los soviéticos a la invasión y agresión de agosto de 1968.

DE NUEVO DE GAULLE

Esas posibilidades de influencia y penetración recíprocas fueron ahora sustancialmente aumentadas con la firma de los tratados internacionales recientemente concluidos por Alemania Occidental con 
la URSS y Polonia, y con el inicio de entendimientos y contactos diplomáticos directos con la República Democrática Alemana. Se trata de una afirmación póstuma del degaullismo, a pesar de estar en un terreno político distinto de aquel contemplado por el General. Willy Brandt intenta, con una Alemania rica e industrializada y preservando sus lazos con el Occidente, realizar, a travẻs de la ostPoLrrrk, aquello que De Gaulle, con toda su imaginación, no consiguió realizar. Así como Pompidou está tratando de realizar en Francia un degaullismo sin De Gaulle, Willy Brandt trata de impulsar a Europa hacia un degaullismo sin Francia. Las ideas del General están ahora por influir en otro país, y no es imposible que, en un plazo relativamente corto, Alemania empiece a poner más dificultades que Francia a la entrada de Gran Bretaña en la Comunidad Económica Europea. También puede suceder que Francia necesite de Inglaterra para neutralizar una Alemania que se afirma política, económica e industrialmente. Por eso mismo, también con el objetivo de neutralizar a Alemania, Francia podrá ser llevada a revisar su actitud en cuanto al Tratado de No Proliferación Nuclear: Alemania hizo, además, inmensas concesiones y algunos sacrificios nacionales. $\mathrm{Al}$ aceptar la permanencia o, al menos, la continuación de la división de Alemania y al aceptar, como definitiva la línea Oder-Neisse como su frontera oriental, en el reciente acuerdo concluido con Polonia, Willy Brandt reveló hasta qué punto está dispuesto a llevar una ostPolitik que también se caracteriza como REALPOLITIK.

Es obvio que. Alemania Occidental espera que esas concesiones y sacrificios sean compensados por una mayor irradiación y movilidad diplomática. Los acuerdos recientemente concluidos crean problemas y peligros para Alemania y para el Occidente, mas no dejan de crearlos, en un grado posiblemente mayor, para la Unión Soviética y el bloque socialista. De cualquier manera, hay que señalar que el nuevo entendimiento germano-ruso constituyó el hecho más importante del año 1970.

\section{CONFRONTAGIÓN Y SUPERVIVENGIA}

El conflicto en el Medio Oriente presenta a nuestro entender, la mejor ilustración de la simultaneidad de confrontación y negociación en las relaciones entre las dos superpotencias. No hay duda de que los intereses americanos y soviéticos se contraponen, de manera nítida y concreta, en toda esa área geopolítica. Consideramos también al Medio Oriente como un área realmente crítica, aquella 


\section{ESTUDIOS INTERNAGIONALES}

que presenta más peligros y amenazas a la paz y a la seguridad internacional. Lo tomamos como potencialmente mucho más explosivo que el conflicto de Indochina, que parece en proceso de fading away y donde no existe una confrontación directa de superpotencias. Parecen, además, bastante reducidas por ahora las posibilidades de una implicación directa de China en el conflicto. Los Estados Unidos de América se encuentran en un verdadero dilema, porque no admiten ni la posibilidad de una continuación indefinida del conflicto ni la posibilidad de abandonar sus posiciones en Asia. Colocado el problema en esos términos, sólo un milagro podría ahora satisfacer a la opinión pública americana. La política de vietnamización representaría, evidentemente, una salida para el dilema y para la impasse, pero esa política de vietnamización es todavía, en la mejor de las hipótesis, una gran incógnita y una gran interrogación.

Existe por el momento, un cierto wishful thinking por parte de los Estados Unidos de América que concierne a la posibilidad de pedir ayuda a la diplomacia soviética para solucionar uno y otro problema, esto es, el problema de Indochina y el problema del Medio Oriente. Ahora bien, la Unión Soviética no tiene el menor interés en liquidar esas dos áreas de conflicto, que le están pagando altos dividendos políticos. La concentración de esfuerzos y de atención en el sudeste de Asia impide a los Estados Unidos una acción más decisiva en áreas más importantes y más cruciales, y la persistencia de la tensión en el Medio Oriente está posibilitando una penetración y una infiltración jamás soñada por los rusos.

Es evidente que la Unión Soviética desea, de cualquier manera, evitar una confrontación nuclear o simplemente militar con los Estados Unidos de América, y que atenúa sustancialmente sus posiciones, cada vez que esos conflictos se tơman más agudos y más explosivos. Eso ha sucedido más de una vez. No hay duda, entretanto, que en el juego peligroso del brinkmanship los soviéticos llevan su acción y su intervención hasta un punto cercano a la eclosión de un conflicto de mayores proporciones. Todo eso confirma nuestra opinión sobre la simultaneidad de la negociación y de la confrontación en la continuidad de la política de détente entre las dos superpotencias, en busca de acuerdos de supervivencia.

Es difícil hacer un pronóstico seguro sobre el futuro de la détente. Eso dependerá de muchos factores latentes en la política internacional y también, de manera preponderante, en el desarrollo de los acontecimientos políticos internos de la Unión Soviética. Por el momento, tanto la Unión Soviética como los Estados Unidos de América parecen interesadísimos en conseguir esos acuerdos de supervivencia, y la mejor ilustración de eso reside en las negociaciones 
SALT que se manejan intermitentemente en Viena y en Helsinki. Otro ejemplo podría ser citado en lo que se refiere a las negociaciones para una solución pacífica del problema del Medio Oriente. Los contactos diplomáticos prosiguen con carácter de perfecta continuidad, no obstante sus resultados positivos, en uno o en otro caso.

Sólo en ese contexto, que vigoriza simultáneamente la confrontación, puede ser acogida la teoría que enfatiza las áreas de la convergencia entre los EE.UU. y la URSS, derivadas no sólo de las peculiaridades de las posiciones estratégicas de disuasión nuclear recíproca, sino también de las condiciones comunes de sociedades industrialmente desarrolladas. Después de eso, postula esta teoría que los EE.UU. y la URSS, por disfrutar de una situación privilegiada de poder, tendrian intereses comunes en el orden mundial para evitar el surgimiento de potencias que puedan disputarles su hegemonía, y en huir de confrontaciones directas por cuestiones que no parecen vitales para su prestigio y su poder. Los intereses comunes, sumados a la posición de ambos países, serían la base concreta de una cooperación creciente entre los EE.UU. y la URSS, con el fin de orientar los acontecimientos en el sentido del mantenimiento de lo que considerarían un mínimo de orden y estabilidad internacionales.

\section{LO ESENCIAL $Y$ LO GOLATERAL}

En lo tocante al problema del desarme parece existir un acuerdo tácito entre las dos superpotencias para desviar el énfasis del desarme general y completo, ahora tenido como utópico y quimérico, hacia las llamadas "medidas colaterales" del tipo del Tratado de No Proliferación Nuclear y del Tratado para la Desnuclearización de los Fondos Marinos y Oceánicos. Existe también un cierto acuerdo tácito entre las dos superpotencias para desviar el énfasis del desarme nuclear hacia el desarme convencional, con cierta tónica en medidas de tipo meramente regional.

Las negociaciones del Tratado de No Proliferación pusieron en descubierto las vacilaciones de ambas superpotencias en asumir compromisos, en el campo del desarme nuclear, que fueron más allá de las disposiciones inocuas e inexpresivas del artículo $6^{\circ}$ del referido tratado. Las negociaciones SALT representan, como dijimos, apenas una tentativa para la eliminación del over overkill y todo indica que las negociaciones conducidas por las dos superpotencias, en el campo del desarme, buscan la estabilización antes que la eliminación del poder militar.

Debe decirse además, que el problema del desarme no podrá ser 
resuelto en abstracto, sino que está íntimamente identificado con el problema de la seguridad colectiva y con el proceso general del relajamiento de tensiones.

Nadie se desarma en un campo de batalla, y el mundo actual de ninguna manera podría ser considerado como un mundo pacífico. Prevalecen todavía teorías de balanzas de poder y de esferas de influencia, ilustradas éstas, de manera flagrante, en la extravagante y ruda doctrina Breznev de la "soberanía limitada" que viola todos los principios hasta ahora tenidos como asentados en el campo del Derecho Internacional Público.

El eventual éxito de las negociaciones SALT y la efectividad de otras "medidas colaterales" tendrían, evidentemente, importantes consecuencias de carácter financiero y presupuestario y podrían también répresentar un poderoso estímulo para el proceso de détente, pero no pueden en rigor ser considerados como pasos concretos y decisivos en el sentido de que se alcancen los objetivos del desarme general y completo.

Todo el énfasis se pone ahora en lo "colateral". Se está haciendo muy poco en el sentido de la solución del problema en su esencia. En materia de negociación de un tratado de desarme general y completo, la Conferencia del Comité de Desarme, en Ginebra, nunca superó la fase de disensión de dos o tres párrafos de un hipotético preámbulo de un aún más hipotético tratado, lo que lleva a algunos a preguntarse si realmente está en vigor el acuerdo Zorin-Stevenson, que desde 1961 constituía el punto de partida de todas las discusiones en el campo del desarme.

UNO POR GIENTO DE LOGURA HUMANA

Los países en desarrollo han tomado en la ONU una posición bastante firme en, lo que toca a la necesidad de perseverancia en los esfuerzos para el desarme general y completo, convencidos como están, de que la persistencia de la presente carrera de armamentos está desviando hacia actividades bélicas recursos preciosos, que podrian estar siendo utilizados en el campo del desarrollo económico.

El mundo está consumiendo cerca de doscientos mil millones de dólares por año en gastos de carácter militar, lo que representa mil veces más que todo el presupuesto clel Programa de Naciones Unidas para el Desarrollo Económico. En reiteradas ocasiones, anotamos el hecho de que si dedicásemos apenas el uno por ciento de ese total a programas de desarrollo, sólo eso multiplicaría por diez, o posiblemente por más, todos los esfuerzos de desarrollo. 
Decíamos que nosotros reclamábamos sólo el "uno por ciento de la locura humana", ya que las esperanzas más optimistas sobre este particular eran que esos armamentos nunca serian utilizados, y por eso mismo, representan gastos inútiles o insensatos. Admitir que esos armamentos son necesarios, que ellos serán utilizados un día, sería admitir la posibilidad de la destrucción total de la humanidad.

\section{OPERAGIÓN DE PAZ}

Otro campo que merece una consideración especial es el de las llamadas "Operaciones de Paz" del tipo de las que se aprobaron para el área de Suez y para Chipre. Esas Operaciones de Paz no se sitúan ni en el Capítulo VI ni en el Capítulo VII de la Carta de San Francisco, y el Brasil ha insistido reiteradamente en la necesidad de un capítulo especial, que discipline esas operaciones, en cualquier proceso eventual de revisión de la Carta de San Francisco.

Esas Operaciones de Paz han suscitado grandes controversias en lo que toca a su custodia y funcionamiento, dada la insistencia de la URSS y de Francia en no reconocer la legitimidad de las mismas sino después de haber sido decretadas por el Consejo de Seguridad y en rechazar la competencia de la Asamblea General para este mismo fin.

EL NUEVO IMPERIO DEL MEDIO

Ningún análisis de la problemática mundial sería completo sin una consideración más detenida de los problemas suscitados por la emergencia de China Comunista como una gran potencia, o más especificamente, como potencia nuclear. La afirmación china alteró profundamente el paralelograma de fuerzas en el Extremo Oriente y es muy posible que las próximas décadas éstas sean fuertemente influenciadas por el contexto de las buenas o malas relaciones de China con una o con otra de las dos superpotencias. El problema es serio, y aunque en un futuro previsible China no puede representar una amenaza tangible ni para los Estados Unidos de América ni para la Unión Soviética, es incontestable que constituye un poderoso factor de intimidación en Asia.

Fue el espantajo de China Continental el que, modificando la política externa de la India, neutralizó mucho la acción india en relación a un buen número de problemas internacionales. Es bastante 
probable que el recelo de una eventual acción militar china pueda haber llevado a la URSS a buscar un modus vivendi en un tratado de No Agresión con Alemania Occidental, y fue ciertamente el recelo de una intervención en masa de los ejércitos chinos lo que impidió a los americanos iniciar una gran escalada general en las operaciones militares en el Sudeste de Asia. De este modo, no obstante su aislamiento diplomático y su alejamiento de la ONU, China comienza a pesar en el libre juego de la política internacional.

Pocos países en la historia se han mostrado tan orgullosos, tan intransigentes y $\tan$ agresivos como China Continental. Existe, a nuestro entender, en Occidente, y tal vez en la. URSS, la tendencia de superestimar el factor ideológico como componente del comportamiento internacional de China. Estamos, por nuestra parte, convencidos de que los chinos son mucho más fanáticos en relación a sus objetivos nacionales que en relación a sus ideas. Debemos citar a este respecto el concepto de Mao-Tsé-Tung según el cual el marxismo es el "instrumento de la revolución china". Y añadía: "China es más importante que cualquier doctrina". A fin de cuentas, la "ideologia" es un vicio occidental, los orientales tienden al empirismo y al pragmatismo. Somos nosotros los que nos mostramos dispuestos a luchar, y, a veces, a morir por ideas, doctrinas y conceptos.

La discusión chino-soviética se basa a nuestro parecer, más en un deseo de afirmación nacional china y a rivalidades con Rusia que a razones propiamente ideológicas. China usa la ideología revolucionaria como un instrumento de su poder nacional.

Es obvio que eso no torna a China ni menos peligrosa ni menos agresiva. Si acentúo el lado pragmático en detrimento del lado ideológico es porque estoy convencido de que no debemos excluir la posibilidad de un considerable ablandamiento de tono de China Comunista en relación a los Estados Unidos de América, si eso conviene a sus intereses político-estratégicos.

China está tratando de romper su aislamiento y de trascender en el plano regional. No tiene otro sentido el activismo político chino (y su disputa con la Unión Soviética por el liderazgo ideológico del movimiento comunista), el desarrollo de un poderío nuclear independiente y la formulación, por Lin Piao, de la tesis de la "revolución de los campos contra las ciudades mundiales" (o sea, la extrapolación de la experiencia comunista china al plano mundial). A pesar de que China se promueve intensamente como la gran fuerza de oposición a la "conspiración" soviético-norteamericana, su influencia permanece, en lo fundamental, restringida a las áreas que le son vecinas.

En ese contexto, podría mencionar las peculiaridades de la situación estratégica de China. En razón de la extensión del territorio, 
localización geográfica, tamaño y dispersión de la población de masas y de organización de guerra de guerrillas, China Continental está en condiciones de resistir a sus adversarios. Aun en la hipótesis de que se usaran medios nucleares, la derrota de China sólo podría ser completada por una ocupación militar, lo que exigiría un ejército de millones de hombres.

Muchos menores son las posibilidades de China de desencadenar una guerra de agresión: por motivos históricos, los chinos siempre tienden a concentrarse en problemas internos, el énfasis en tácticas revolucionarias tiende a minimizar la conquista militar de tipo convencional, y su capacidad logística, en función de su grado de desarrollo económico, no parece suficiente para la conducción de una guerra a distancia, sobre todo porque las limitadas fuerzas aéreas y navales de que dispone no estarían en condiciones de defender sus propias líneas de comunicación.

En términos económicos, China, aunque ha alcanzado progresos sustanciales, es todavía una potencia entre pequeña y media. Su producto nacional bruto, medido por padrones occidentales, corresponde a dos terceras partes del japonés, una cuarta parte del soviético y un octavo del norteamericano. No está claro el presente ritmo del crecimiento del PNB chino.

Por todo eso, se debe evitar el error de superestimar el poder político y militar de China Comunista y no cometer el error de colocarla en pie de relativa igualdad con las dos superpotencias. Una percepción más refinada tal vez llevase a la conclusión de que, en realidad, no existen dos o tres superpotencias, sino apenas una, los EE.UU., que es desafiada por la URSS. China, por su lado, se afirmó como una gran potencia regional. Su eventual dimensión mundial se basa antes en sus posibilidades de desarrollo futuro (inclusive nuclear) y en la guerra verbal que en hechos relevantes para el equilibrio de poder en la actualidad.

LA O.N.U. Y LAS DOS GHINAS

Todo indica que China se aproxima a la fecha de su ingreso a las Naciones Unidas. En la presente Asamblea General, China, por primera vez, se aseguró una mayoría simple (de 51 contra 49 votos) para su admisión, y la regla de los dos tercios que impidió su ingreso, el 20 de noviembre pasado, comenzó a demostrar síntomas de debilitamiento. $Y$ hay indicios de atenuación en la posición de los EE.UU., que ya no se opone frontalmente a la admisión de China Continental, pero siempre se opone a la exclusión de China Nacionalista. No será 


\section{ESTUDIOS INTERNAGIONALES}

fácil, entretanto, la implementación de una "política de las dos Chinas", ya que a esa política se opone cada una de ellas. De este modo, a menos que China en un futuro próximo cometa algún acto deliberado de agresión o nuevamente opte por el aislamiento, no es imposible la admisión de China Comunista en la próxima asamblea de $1971^{1}$.

Eso, evidentemente, traerá grandes problemas a la Organización, sobre todo en lo que se refiere al funcionamiento del Consejo de Seguridad, que posiblemente atravesará un nuevo período de inmovilización por veto o por amenaza de veto. Conviene, además, observar que la simple presencia de China podrá ejercer una acción negativa sobre la actual tendencia soviética, para unirse, muchas veces, a un "consenso" en el Consejo de Seguridad. La presencia de China, con su eterna censura de lo que llama "coalición de imperialistas y revisionistas" podrá ser un factor de inhibición para la Unión Soviética, que no desea despojarse totalmente de sus remanentes características revolucionarias.

CONFRONTACIÓN DE PODER Y ÁREAS DE IDENTIDAD

Decimos que subsistía y posiblemente subsistirá la confrontación de poder entre la URSS y los EE.UU. Resta por ver la influencia de China en ese proceso de confrontación. Por el momento debe decirse que al margen de esa confrontación de poder y de esa confrontación ideológica, que une a las dos superpotencias, comienzan a caracterizarse algunas áreas, que presentan cierta "identidad de intereses" entre las dos superpotencias.

Esto se torna particularmente evidente en las Naciones Unidas, donde hoy son relativamente pocos los problemas que podrían, en rigor, ser definidos en términos de Este-Oeste. Por el momento no se nos ocurre sino uno: el problema de Corea, cuyo debate anual parece más bien un rito otoñal que un verdadero debate. Argumentos, discursos, votaciones, polémicas, sobre invitaciones a Corea del Norte, se repiten todos los años, con una acrimonia ya bastante desgastada por el cansancio y la monotonía.

Además sería válido preguntarse si con las transformaciones que se operan en el mundo, con el desvanecimiento de la política de alianzas, con la nueva emergencia económica de Europa, con los efectos políticos del degaullismo y con el incipiente degaullismo germánico,

${ }^{1}$ Debe recordarse que este artículo está basado en una conferencia pronunciada en diciembre de 1970 ( $N$. de la $R_{\text {. }}$ ). 
todavía se debería hablar de confrontación Este-Oeste, o si sería más lógico o más preciso hablar de confrontación URSS-EE.UU. El mundo socialista pierde sus características monolíticas y tiende a diversificarse en términos ideológicos. La URSS está hoy, no sólo geográfica sino también ideológicamente, en el centro del mundo socialista y está siendo desplazada al este y al oeste, a la izquierda y a la derecha.

Si existe hoy en las Naciones Unidas un movimiento de insatisfacción, esto es, un grupo de países con reivindicaciones precisas en el campo del desarrollo económico y social, a ese movimiento ciertamente no pertenecen los países socialistas, extremadamente conservadores y aun retrógrados en todos los asuntos relacionados con el comercio internacional. En materia de comercio y desarrollo, los países socialistas operan, en el campo internacional, en términos casi clásicos de liberalismo económico, de laissez-faire, laissez-passer.

\section{5 y 1967: EL. CONGELAMIENTO DEL PODER}

El punto más alto de la détente parece ser evidentemente el 'Tratado de No Proliferación Nuclear, condición, según todo indica, impuesta por la Unión Soviética como sine qua non para la continuación del proceso de relajamiento de tensiones internacionales. El tratado buscaba y busca, primordialmente, el impedir la nuclearización militar de Alemania y de Japón, países derrotados en la Segunda Guerra Mundial, y se vincula de este modo al esfuerzo, ya reflejado en la Carta de las Naciones Unidas, con vistas a la inmovilización del cuadro político-estratégico de 1945.

Las superpotencias realizan un esfuerzo conjugado en el sentido de una estabilización y congelamiento del poder mundial, en función de dos fechas históricas arbitrarias: 24 de octubre de 1945, fecha de la entrada en vigor de la Carta de las Naciones Unidas y 10 de enero de 1967, fecha límite para que los países se habilitasen como potencias militarmente nucleares, en términos del Tratado de No Proliferación Nuclear.

El Tratado, que se interpreta como un complemento de la Carta en el proceso de estabilización del poder mundial, viola entretanto varios de sus propósitos y principios en la medida en que establece distintas categorías de naciones: una categoría de países fuertes y, por lo tanto, adultos y responsables, y una categoría de países débiles y, por lo tanto, ni adultos ni responsables.

El Tratado procede de la premisa de que, contrariamente a toda evidencia histórica, el poder trae consigo la prudencia y la moderación. 
Institucionaliza la desigualdad entre las naciones y parece aceptar la premisa de que los países fuertes se tornarán cada vez más fuertes y de que los países débiles se tornarán cada vez más débiles.

Francia y la República Popular China no firmaron el Tratado de No Proliferación, pero, ya sea que lo firmen eventualmente, ya que persistan en su actitud actual de rechazo y abstención, esos dos países solamente ganarían con su vigencia e implementación.

El Tratado no impone limitaciones a los países militarmente nucleares (a no ser de no trasmitir tecnología militar para fines militares a los países no militarmente nucleares, y ningún integrante del restrictivo y exclusivo Club Atómico parece demasiado interesado en proporcionar tal tipo de asistencia). Francia y China Continental podrían también ser los mayores beneficiarios del Tratado de No Proliferación en la medida en que, neutralizando nuclearmente a Alemania Occidental y Japón, puedan conservar un cierto tipo de supremacía en sus respectivas áreas geopolíticas. La firma del Tratado de No Proliferación se debe más bien a una jugada de tipo político del General De Gaulle que a intereses estratégicos de Francia que, repito, nada perdería, sino más bien ganaría con su firma y ratificación.

Por otro lado, el Tratado de No Proliferación extiende al campo de la ciencia y tecnología ciertos privilegios y prerrogativas que la Carta de las Naciones Unidas limitara, en el campo específico de la paz y la seguridad, a los cinco miembrós permanentes del Consejo de Seguridad. Y conviene observar que, por causa del sindrome de las dos caras de China, los cinco miembros permanentes del Consejo no coinciden exactamente con las cinco potencias nucleares actuales.

La tendencia hacia la estabilización y congelamiento del poder mundial se revela igualmente en el rechazo de los cinco miembros permanentes del Consejo de Seguridad para aceptar cualquier debate y discusión sobre la posibilidad de una eventual revisión de la Carta de las Naciones Unidas. Cualquier revisión de la Carta sólo podría ser aprobada con el voto convergente de los cinco miembros permanentes del Consejo de Seguridad, y es evidente que ninguno de esos miembros concordaría en despojarse voluntariamente de los privilegios y prerrogativas que les fueron conferidos por la Carta de San Francisco, o en extender a otros estados miembros esos mismos privilegios y garantías. La Carta de San Francisco y el Tratado de No Proliferación se tornan, de esta manera, en los dos instrumentos básicos de todo un proceso de estabilización del poder mundial. 
EL DIVIDENDO Y EL DIVISOR

Existen, entretanto, otros factores que comienzan a afirmarse dentro de ese mismo proceso de estabilización. Nos referimos específicamente a algunas tendencias que se manifiestan en el tratamiento de los problemas de población y preservación del medio humano.

Se afirma ahora que la llamada population bomb podrá resultar más fatal y más nefanda que la misma bomba nuclear y se acentúa una tendencia para tratar el problema en bases uniformemente universales, con la omisión de que el problema, de competencia exclusiva de cada estado, en el ejercicio de su plena soberanía, tiene que tomar en cuenta hechos y circunstancias de carácter peculiarmente nacional.

Nadie duda que existen estados superpoblados, pero nadie debe olvidar que algunos estados, como por ejemplo el Brasil, no obstánte sus ochenta y tres millones de habitantes, requiere un crecimiento demográfico en consonancia con el pleno aprovechamiento de sus recursos naturales.

Tratar de resolver el problema en abstracto, en términos marcadamente fríos y estadísticos, sin tomar en cuenta una serie de factores importantísimos en el planteamiento del problema general del desarrollo, parece una actitud poco técnica, desprovista de lógica, y destinada, de este modo, al fracaso político. Se argumenta que el crecimiento demográfico neutraliza las ventajas del crecimiento del Producto Nacional Bruto en el avalúo de la renta per capita, tomada ahora, de manera un tanto simplista, como único índice de desarrollo económico.

En una palabra, en vez de insistir en el aumento del dividendo, o sea, del Producto Nacional Bruto, se insiste ahora en la inmovilización del divisor. Dicho en otras palabras: se trata de convertir el grave problema del subdesarrollo en un mero problema de estabilización, con el olvido del hecho de que si fuésemos a estabilizar a muchos países en el nivel económico actual, procederíamos a la estabilización. de un nivel extremadamente bajo.

DE NUEVO, EL SAIVAJE FELIZ

Por otro lado, en la consideración de los problemas relativos a la preservación del medio humano, se tiende a colocar una tónica demasiado fuerte en los peligros de la rápida industrialización. Se acentúan 
los peligros de la contaminación, ciertamente graves para los países altamente industrializados, cuando la mayor parte del planeta todavía vive en una etapa de pre-contaminación, o en otras palabras, todavía no ha tenido la oportunidad de ser contaminada. Dos terceras partes de la humanidad están mucho más amenazadas por el hambre y por la penuria que por los males de la contaminación. Es claro que los países en desarrollo no quieren incurrir en los mismos errores en que incurrieron los países altamente industrializados, pero es evidente también, que no podríamos aceptar la resurrección en pleno siglo $\mathrm{xx}$ de la teoría del "salvaje feliz" de Rousseau, que dio sabor y colorido a todo el romanticismo francés.

"Conserven sus bellas playas, no dejen que a sus ciudades les acontezca lo que a Nueva York o a Londres". Esas son frases que constantemente martillean los tímpanos de los representantes de los países subdesarrollados. Ahora bien, los países en desarrollo parten de la premisa de que cualquier programa adecuado para la preservación del medio humano debe tener en cuenta los factores básicos del subdesarrollo, ya que éste representa por sí solo una de las peores formas de contaminación del "environment".

Ese énfasis en los peligros de la explosión de la población y en los peligros de una industrialización extremadamente rápida no parecen muy distantes de la política del Banco Mundial en materia de desarrollo.

Nadie pone en duda la necesidad de medidas prontas y eficaces, algunas de las cuales recaen en el ámbito de la cooperación internacional, con vistas a combatir la contaminación y a preservar el medio humano. Lo que parece indispensable es que esas medidas no sean tomadas en abstracto, sin que se consideren las necesidades vitales del desarrollo económico.

Los países en desarrollo sólo pueden ver con aprensión una tendencia hacia una política de estabilización de poder que coloca todo el énfasis en el desarme regional, control de población, de estímulo al uso de la energía nuclear para fines pacíficos y de desestímülo a un rápido poder de industrialización.

DE LA PAZ A LA TECNOLOGÍA

El recelo actual es que se afirme una tendencia para considerar el problema de seguridad internacional como un mero capítulo de la détente, 'o mejor, de las relaciones recíprocas entre las dos superpotencias, y para reducir a la ONU a las proporciones de un mero Instituto Internacional de Tecnología, que se ocupe de aspectos de 
cooperación internacional en asuntos como población, preparación del medio humano, etc. Todos esos asuntos son importantes pero podrían, en ciertos casos, ser confiados a la atención de algunas agencias especializadas. A fin de cuentas, la ONU es la única agencia especializada para los problemas de paz y de seguridad internacional.

\section{MLÁS ALLÁ DEL HEMISFERIO}

Al tratar ahora la segunda parte del tema " $\mathrm{EI}$ Continente Americano dentro de la Problemática Mundial" me veo forzado a hacer algunas precisiones iniciales. Está claro que, en la primera parte de este trabajo, tenemos que analizar detenidamente la posición de los Estados Unidos de Ámérica, cuyos intereses van mucho más allá del Hemisferio y trascienden con mucho los límites exiguos del panamericanismo que todavía pretendemos desarrollar. No obstante su reconocida vocación psicológica para el aislacionismo, los Estados Unidos por razones históricas fueron lanzados de manera irreversible, al juego de la política mundial. De ahí el concepto de diplomacia total y tal es la fuerza militar, política, económica y tecnológica de los Estados Unidos, que este país será fatalmente llamado a pensar en el mundo que lo circunda antes de pensar en el continente en que geográficamente se sitúa. Por eso mismo, existirán ciertas dificultades conceptuales en el tratamiento de un enunciado que parece presuponer una completa organización político-estratégica del continente americano delante de los problemas del mundo contemporáneo. Es, por otro lado, irrecusable que los problemas mundiales van a influenciar de manera cada vez más directa y de manera cada vez más decisiva, los rumbos políticos y sociales de cada uno de los países que componen el "continente" americano.

CONTINENTE $\times$ HEMISFERIO

A nuestro orgullo de habitantes y nacionales de América del Norte, de América Central y de América del Sur, el concepto de hemisferio es más grato y más lisonjero que el concepto de continente. $A$ fin de cuentas, el mundo cuenta con cinco continentes y apenas con dos hemisferios. Al hablar de hemisferios nos sentimos así una parte mayor del mundo terrestre.

Esos conceptos de hemisferio y continente, que no ofrecen grandes dificultades semánticas en el terreno de la geografía, se tornan, 
entretanto, extremadamente fluidos e imprecisos cuando son trasladados al terreno de los acontecimientos políticos contemporáneos. Porque, no obstante una actitud común de defensa y de asistencia que se traduce en la Organización de Estados Americanos, en el Tratado Interamericano de Asistencia Reciproca y en organizaciones como el Colegio Interamericano de Defensa, difícilmente podríamos colocar la posición de Estados Unidos de América en términos similares -o idénticos- a la posición de América Latina frente a los diferentes items de la problemática mundial.

La amplia solidaridad, demostrada en la Segunda Guerra Mundial, entre los Estados Unidos de América y los países latinoamericanos, se manifiesta claramente en el campo de la defensa y la seguridad. Los compromisos militares latinoamericanos para con los Estados Unidos de América son para este país consecuencia de su calidad de "país del hemisferio", y no de su calidad de "Iíder de la coalición occidental" ya que el Tratado Interamericano de Asistencia Recíproca delimita de manera muy precisa, su área de aplicación.

La distinción es, entretanto, más teórica que real, ya que nadie duda que en una seria confrontación mundial el continente americano cerraría filas en torno a los Estados Unidos de América. Eso sucedió en 1962, cuando ocurrió la crisis de mísiles soviéticos en Cuba. Tradicional, política y geográficamente, los países latinoamericanos no desean otra alternativa.

Entretanto, en el terreno económico, como ocurrió en el "Consenso de Viña del Mar", los países latinoamericanos han encontrado un terreno de solidaridad común para la discusión y negociación de ciertos asuntos con el gobierno de los Estados Unidos de América. Nuestra unidad de posición frente a los problemas de la seguridad mundial va acompañada por una gran diversidad de actitudes en lo que se refiere a los problemas de desarrollo económico y social, y eso es revelado a la sociedad no sólo en las Nacionas Unidas sino en el propio ámbito de la Organización de Estados Americanos.

\section{EL AISLACIONISMO}

A través de su historia, los Estados Unidos han tenido la preocupación, por un lado, de no verse envueltos directamente en disputas y controversias entre países europeos, y por otro la preocupación de no permitir la ingerencia europea (anteriormente nadie pensaba en la posibilidad de otras interferencias) en asuntos del Hemisferio Occidental. Además de esos objetivos, existía la preocupación de que fuese mantenido un cierto "equilibrio de poderes" en Europa. No 
se daban evidentemente las condiciones para que la hegemonía americana pudiese ser desafiada desde dentro del continente. La doctrina Monroe era, por lo tanto, una clara advertencia a Europa.

El llamado aislacionismo americano ha atravesado varias vicisitudes. Es un fenómeno intermitente, que desaparece o repunta en determinadas circunstancias y es adoptado por uno u otro grupo de acuerdo a circunstancias de carácter político-ideológico. Se mezcla, frecuentemente, con manifestaciones de carácter pacifista. Rंecuérdese que provenían de la derecha las principales objeciones a cualquier envolvimiento importante americano en la Segunda Guerra Mundial. Recuérdese los esfuerzos de Franklin Delano Roosevelt para caminar en el sentido de una ley de lend. lease, que representaba el primer paso para esa participación.

Entretanto, los mismos elementos liberales (y digo liberales en el sentido americano y no en el sentido europeo del liberalismo económico) que apoyaron la tendencia globalista de Franklin Roosevelt, son los que hoy se oponen tenazmente à un continuado compromiso americano en el Sudeste de Asia. La acción americana se dirigía entonces contra el expansionismo de extrema derecha, en cuanto hoy se dirige contra el expansionismo de extrema izquierda.

Es de notar, además, que en este momento, muchos de los elementos que más cerradamente se oponen a la conducción y continuación del conflicto de Indochina no dejan de reclamar una acción americana más enérgica y más eficaz en el área política del Medio Oriente.

Las actitudes en lo tocante al aislacionismo han estado, como dijimos, influenciadas por posiciones políticas o ideológicas. Debe decirse también que ese fenómeno aislacionista se aplicó, de manera uniforme, a Asia y a Europa.

Se habla ahora de un fenómeno de neoaislacionismo, pero es evidente que, aun en la hipótesis de un retraso de las posiciones americanas en Asia, en virtud del largo y exhaustivo conflicto de Indochina, la vuelta al antiguo aislacionismo es inconcebible $y$, ciertamente, debe excluirse. También hay que decir que cualquier recurrencia limitada del conflicto aislacionista difícilmente podría, a esta altura, afectar Ias relaciones de los Estados Unidos de América en Europa Occidental y en América Latina. Por el contrario, podría también suceder que una preocupación menos obsesiva por los problemas asiáticos desviase, con más énfasis, la atención americana para áreas más próximas y con las cuales posee mayores afinidades politicas y culturales.

De cualquier manera, sería anacrónico y antihistórico imaginar que los Estados Unidos de América puedan resignarse a una política de "capitalismo en un solo país", o aun sólo en el Hemisferio Occi- 
dental. A mediano y largo plazo, esa línea sería insostenible, pues provocaría una redistribución del poder en el mundo inaceptable para los Estados Unidos de América.

A propósito, el profesor Zbigniev Brzezinski, de la Universidad de Columbia, usa las siguientes palabras en un artículo del periódico The Washington Post:

"Es simplista y engañador medir la participación norteamericanä en los problemas mundiales por el número de tratados de seguridad firmados con países extranjeros. Es mucho más significativo $-\mathrm{y}$ revelador- examinar el crecimiento del compromiso americano en la economía mundial a través de su participación en corporaciones internacionales y en inversiones extranjeras, a través de la expansión en el número de empresarios extranjeros asociados directa o indirectamente con firmas norteamericanas, a través del flujo creciente de estudiantes extranjeros hacia los Estados Unidos de América y de americanos hacia el exterior, por el apoyo activo de los EE.UU. a arreglos regionales de cooperación política y económica, y a través de la intensificación del flujo de comunicaciones entre los Estados Unidos de América y el resto del mundo".

El hecho de que los EE.UU. adoptaran un perfil externo menos sáliente no significa que estén abandonando sus posiciones políticas y económicas. La postura de introspección pertenece a un pasado que no vuelve más. La tesis de la "fortaleza americana" está definitivamente archivada. Los Estados Unidos de América, es obvio, no tienen la intención de abandonar sus intereses, responsabilidades y pósiciones en Europa, Medio Oriente, Asia y África.

SEGURIDAD INTERNAGIONAL Y SEGURIDAD PARA TODAS IAAS NACIONES

En la primera parte de este trabajo tratamos de señalar que el concepto de paz no tiene la misma significación para la generalidad de las naciones. Por fuerza de sus responsabilidades mundiales e impulsadas por los problemas de su propia confrontación recíproca, las superpotencias tienen que pensar en términos globales, mediante conceptos de "diplomacia total". Esto quiere decir que las superpotencias no pueden ya permitirse reacciones sectoriales o regionales, sin una evaluación previa de los efectos y consecuencias de tales reácciones en el contexto general y global de su política externa.

Los EE.UU. no pueden, por ejemplo, tomar iniciativas importan- 
tes en el Sucleste de Asia y en el Medio Oriente sin evaluar precisamente la repercusión de tales iniciativas en el cuadro general de las relaciones (o de la falta de relaciones) con la Unión Soviética y con China Comunista. Todo eso lleva a las superpotencias a un concepto de paz que se reduce, en último análisis, a un grado tolerable de conflictos y de tensiones internacionales. Existe una tentencia para considerar la paz internacional como un simple capítulo de la détente y para situarla exclusivamente en el texto de las relaciones entre los EE.UU. y la URSS.

En el ámbito de la Asamblea General de las Naciones Unidas, ciertos países latinoamericanos se han opuesto a este tipo de filosofía, que entregaría todas las decisiones importantes a un Directorio de Grandes Potencias, a una diarquía o tal vez, en la mejor de las hipótesis, a una pentarquía nuclear. Para los países medios y pequeños, la paz, como dije, tiende a traducirse en seguridad y más específicamente en seguridad para todas las naciones.

\section{NACIONALISMO $Y$ SUPRANACIONALISMO - INDEPENDENCIA E INTERDEPENDENCIA}

En el ámbito de las Naciones Unidas, los países latinoamericanos han luchado por la preservación y por la observancia de los propósitos y principios de la Carta de San Francisco, principios y propósitos que corresponden a una verdadera "Declaración de Derechos" para los estados y para las naciones.

Al reclamar la necesidad de una eventual revisión de la Carta de las Naciones Unidas, a fin de adaptarla a las condiciones del mundo contemporáneo (y no podemos vivir eternamente en el año 1945), la delegación de Brasil y algunas otras delegaciones latinoamericanas han afirmado que esos propósitos y principios son tan válidos como lo eran en el momento de su enunciación. Lo que se hace ahora necesario es fortalecer y reactivar esos organismos y mecanismos encargados de su implementación. Entre esos principios figuran los de la igualdad soberana de todos los estados, el de no intervención, el de prohibición del uso de la fuerza o de la amenaza de la fuerza para la solución de disputas internacionales, el de integridad territorial y el de no interferencia en asuntos internos de otros estados.

Es claro que, así como en cada estado nacional la defensa de los derechos y garantías individuales interesa más a los individuos que a los poderes públicos, la defensa intransigente de los propósitos y principios de la Carta interesa más a los estados medios y pequeños que propiamente a las grandes potencias, que se apoyan en un es- 
quema de poder para defenderse. Por eso mismo, los países menores, interesados en defender su plena soberanía, han resistido la presión de algunos conceptos de supranacionalismo e interdependencia, que tenderían a no reverenciar ciertos principios inscritos en la Carta de San Francisco.

Se afirma la necesidad del establecimiento de algunos órganos supranacionales, destinados a imponer restricciones y limitaciones en asuntos como los de la preservación del medio humano, población, no proliferación, etc., argumentando que las nuevas condiciones del mundo tornan obsoletos y superados ciertos conceptos de soberanía $\mathrm{e}$ independencia.

Ahora bien, nadie duda de que el progreso de las relaciones internacionales para ser efectivo y duradero, tendrá que asentarse en ciertas premisas de interdependencia y en ciertas bases supranacionales. Eso es evidente. Lo que sustentamos es que esta etapa de supranacionalismo y de interdependencia presupone una etapa previa de soberanía y de total independencia política y económica.

En suma, lo que sostenemos es que, antes de declarar obsoletos y superados estos principios de la Carta, tenemos que respetarlos e implementarlos. En primer lugar, respetemos y transformemos en realidad el principio de igualdad soberana de los estados. Después de eso, como países iguales y soberanos, hagamos las concesiones necesarias en favor de un concepto más generoso y menos estrecho de cooperación entre los estados.

No existen indicios de ninguna concesión de principio por parte de las superpotencias en cualquier asunto que afecte de cerca su seguridad y sus intereses políticos y económicos. Las negociaciones sobre desarme nuclear y sobre cuestiones comerciales son bastante reveladoras en ese particular.

Es así perfectamente comprensible que los países menores se aferran a los propósitos y a los principios que, a pesar de ser violados constante y repetidamente, los ayudan a defenderse de presiones políticas y diplomáticas.

Por eso mismo, el sentimiento nacionalista solamente desaparecerá cuando sea establecido un sistema adecuado de justicia distributiva entre las naciones. Mientras eso no suceda - y nada indica de que estamos próximos a ese objetivo- el derecho, o tal vez el mismo deber de cada estado es el de promover la defensa activa de sus intereses $y$ de sus fronteras.

Evidentemente, los países mayores y más fuertes pueden darse el lujo de ser mucho menos afirmativos en relación a su soberanía y a su nacionalismo. Lo nacionalista es, en muchos casos, una actitud de defensa y una postura defensiva en el campo internacional. Por eso, persistirá por mucho tiempo, hasta que paulatinamente se vayan 
modificando y humanizando las reglas de convivencia entre las naciones.

EL DOCUMENTO LATINOAMERIGANO DEL 7 DE OCTUBRE

El día 7 de octubre de 1970, veintitrés países latinoamericanos, esto es, todos los estados miembros latinoamericanos, con excepción de Cuba, presentaron en la XXV Asamblea General de la ONU un documento de gran importancia, que corresponde en el plan politico y diplomático, al Consenso de Viña del Mar en el campo económico. Se trata de una afirmación de América Latina ante los problemas de paz y seguridad mundial. Ese documento tomó en la Comisión Política la sigla A/C. I/L.517 y constituye hoy el elemento básico de las discusiones sobre el ítem "Consideración de medidas relativas al fortalecimiento de la seguridad internacional".

En nombre de veintitrés estados miembros latinoamericanos, declaré lo siguiente al presentar formalmente el proyecto de resolución en consideración:

"El proyecto no se propone ofrecer soluciones específicas para esta o aquella cuestión que pueda hacer peligrar o crear problemąs. para la paz y la seguridad mundiales. Se destina claramente para remediar otros aspectos de una indescifrable crisis institucional en las Naciones Unidas y a neutralizar ciertas tendencias, cuya persistencia condenaría a la Organización a la impotencia y a la inoperancia. En una palabra: el proyecto de resolución busca el fortalecimiento de las Naciones Unidas como institución política y centro de actividad y negociación diplomática. No procura una solución directa o mágica para la crisis internacional, sino una solución para la crisis institucional de las Naciones Unidas.

Los veintitrés países patrocinadores del proyecto de resolución no consideran la paz como inexistencia de guerra o como un estado tolerable de tensiones. Buscan, como está expresado en el segundo párrafo del prólogo del proyecto, una paz mundial basada en la justicia y destinada a garantizar la seguridad de todas las naciones.

El proyecto reafirma, solemnemente, que una paz verdadera y una seguridad auténtica exigen de todos los estados, grandes y pequeños, el estricto respeto a los principios y el cumplimiento cabal de los propósitos de la Carta de las Naciones Unidas, así como la fidelidad a los ideales y a las normas de su prólogo.

Por esa misma razón, todos los esfuerzos en el sentido de fortalecer la seguridad internacional y la détente, tendrán resultados duraderos irreversibles siempre que se realicen dentro del ámbito de la Carta de San Francisco y busquen establecer un orden interna- 
cional que asegure la justicia para todos los estados y para todos los hombres. No queremos, evidentemente, una paz que sea mera perpetuación de condiciones de guerra.

Los patrocinantes de este proyecto de resolución consideran los propósitos y principios de la Carta como una verdadera declaración de derechos para los estados, los pueblos y las naciones.

El proyecto reafirma, solemnemente, que en caso de conflicto, entre las obligaciones contraídas dentro de la Carta para los miembros de las Naciones Unidas y las que fueron contraidas en cualquier otro convenio internacional, las obligaciones impuestas por la Corte han de prevalecer. Ningún principio nos parece más vital y más importante, en la medida en que establece la primacfa de la Carta y, por otro lado, la primacía de los propósitos y principios sobre todas las normas de conducta internacional. El artículo 103 de la Carta de San Francisco, conjugado con la afirmación simultánea de los propósitos y principios, torna ilegítima e ilegal la amenaza y el uso de fuerza contra la integridad territorial de un estado, cualesquiera sean los tratados y las alianzas que se puedan invocar dentro de un contexto determinado.

Deseo recordar algunos conceptos que recientemente tuvimos oportunidad de expresar. ¿Por qué, preguntamos, las Naciones Unidas deben ser tan cautelosas y refractarias para asumir obligaciones por pactos concretos bilaterales o multilaterales, puesto que el principio de no agresión es ahora más que un principio y en verdad es parte integral del derecho positivo internacional? $\mathrm{La}$ única conclusión, válida y triste, debo decir, es la de que las obligaciones multilaterales de la Carta de las Naciones Unidas, que es un tratado solemne, son llevadas con menos seriedad que las obligaciones bilaterales o multilaterales asumidas a través de tratados específicos. Debemos analizar cuidadosamente esto y explicar porqué las obligaciones pierden importancia y son menos obligatorias y menos prohibitivas en proporción inversa a su grado de universalidad. ¿Por qué una obligación ante la comunidad de naciones debe ser menos imperativa o menos prohibitiva que un compromiso con un determinado estado o grupo de estados?

El proyecto expresa una preocupación grave en lo tocante a la extrema lentitud con que se desenvuelven las negociaciones en el campo del desarme, al mismo tiempo que proclama la necesidad de una acción internacional urgente y común, apoyada en una estrategia global destinada a reducir y eliminar las diferencias entre los países desarrollados y los países en vías de desarrollo, lo que constituye condición indispensable para el establecimiento de la paz internacional y el fortalecimiento de todas -repito- de todas las naciones. 
En la medida en que busca traducir una auténtica posición latinoamericana ante los problemas mundiales, el proyecto de resolución de veintitrés países no podría dejar de reclamar medidas más concretas en pro del desarrollo económico ý del progreso social de todos los pueblos. Tenemos que caminar en dirección y afirmación de un principio de seguridad colectiva en el campo económico, semejante al que hemos tratado de delinear en San Francisco, con bases todavía precarias, en el campo específico de la paz, y en el campo de la seguridad internacional.

Se trata, en una palabra, de determinar si las Naciones Unidas aceptan o no una responsabilidad colectiva en el problema del subdesarrollo. Para los patrocinadores de este proyecto de resolución, el desarrollo económico es condición sine qua non de la seguridad, y esto está perfectamente expresado en el párrafo 8 de la parte dispositiva de nuestro proyecto de resolución. Por eso las delegaciones latinoamericanas no conciben que el proyecto sobre seguridad, no sólo en el sentido más amplio, pueda dejar de preocuparse por uno de los principales factores de inseguridad y desasosiego entre las naciones. Para los autores de este proyecto, la paz se identifica con la seguridad, y ésta se identifica con el desarrollo. Este es el pensamiento básico del proyecto de resolución que nuestros veintitrés países ofrecen a consideración de la Comisión Política.

El proyecto trata, así, de definir una correlación estrecha, intima, entre los tres conceptos: el fortalecimiento de la seguridad internacional, el desarrollo económico de los países en desarrollo y el desarme, de manera que todo el progreso que se alcance en cualquiera de esos objetivos constituirá ún progreso en el sentido de todos ellos. Ese es el pensamiento principal del proyecto de resolución. Proclama que la paz genuina presupone un ejercicio pleno de los derechos humanos y el término de la opresión colonial, y reafirma la vocación universal de las Naciones Unidas. Busca, como medida práctica, reactivar los mecanismos diplomáticos que se ofrecen a las Naciones Unidas mediante una utilización más amplia y más sistemática de los medios y métodos autorizados por el Capítulo VI de la Carta de San Francisco. Esta sería; a nuestro entender, la única forma capaz de devolver al ámbito de las Naciones Unidas la consideración de problemas que ahora se discuten en círculos extremadamente restringidos de las potencias. En una palabra: lo que proponen los veintitrés países americanos es una reactivación del mecanismo diplomático de la Organización. Si queremos rehabilitar a las Naciones Unidas como institución política tenemos que reactivar su acción diplomática, porque tendemos frecuentemente a olvidar e ignorar el aspecto diplomático de las Naciones Unidas que, como 
hoy decimos, es el único organismo especializado para la paz y la seguridad mundiales.

Finalmente, en su último parágrafo dispositivo, los países latinoamericanos, que en la Asamblea de 1969 lucharon por una consideración continua de los problemas de seguridad internacional, piden formalmente la inclusión del tema en el programa provisorio del vigesimosexto período de sesiones. Esto significa que queremos proseguir este importantísimo debate político sin consideraciones de tipo mecánico.

Más que un texto, este proyecto es un llamado para que se cumplan las obligaciones de la Carta. Es un llamado para que las relaciones entre los estados miembros eviten la aplicación de teorías absurdas y superadas de equilibrio de poder, de política de poder y de zonas de influencia. Es un llamado a la justicia y a la libertad. Es una reafirmación de los países que quieren defender sus intereses en el campo de la paz, de la seguridad y del desarrollo, y representa básicamente la posición de América Latina ante los problemas mundiales.

El proyecto representa una posición latinoamericana basada en la idea de justicia $y$, lo que es igualmente importante, una posición latinoamericana de paz basada en el libre ejercicio de la libertad".

Quise extenderme sobre este documento del 7 de octubre de 1970 porque constituye a mi parecer, el más original y el más completo pronunciamiento latinoamericano sobre problemas mundiales. Representa una posición nueva y autónoma de América Latina que, de este modo, asume el liderazgo de los debates sobre paz y seguridad en las Naciones Unidas. Es a la luz de ese documento que se deberán considerar otras iniciativas latinoamericanas en varias otras materias bajo la consideración de la Asamblea General. América Latina ve a las Naciones Unidas como un elemento de paz, justicia y progreso y no como un mero instrumento de mantenimiento del statu quo mundial.

\section{CONTINENTALISMO Y UNIVERSALISMO}

El proyecto latinoamericano del 7 de octubre de 1970 reafirma el principio contenido en el artículo 103 de la Carta de San Francisco, de que en caso de conflicto entre las obligaciones asumidas ante la Carta y cualquier otro acto u obligación internacional, las obligaciones de la Carta deben prevalecer. Esa reafirmación es extremadamente importante, en esta coyuntura histórica, cuando la Unión Soviética pretende justificar la doctrina Brezhnev de soberanía limi- 
tada y episodios como los de la invasión de Checoslovaquia, con la invocación de cláusulas específicas del pacto de Varsovia.

El proyecto latinoamericano repudia formalmente la doctrina Brezhnev y toda y cualquier tendencia para el establecimiento de esferas de influencia en el primer parágrafo operativo, que dice precisamente lo siguiente: "Reafirma solemnemente la validez incondicional de los propósitos y principios de la Carta como base de las relaciones entre las naciones, independientemente de su tamaño, posición geográfica, nivel de desarrollo o sistema político-social".

Es sabido que por el momento, son los soviéticos los más interesados en acentuar el principio de "cooperación regional", justamente con el objetivo de preservar su doninación política y económica sobre los países del este europeo. Por eso mismo, el documento latinoamericano estipula claramente que todo sistema de cooperación regional tiene que asentarse sobre los principios y propósitos de la Carta, o en otras palabras, sobre el principio de igualdad soberana de los estados. Los rusos adoptan ahora algunas de las ideas de Foster Dulles.

\section{DESARROLIO ECONÓMICO}

Los países latinoamericanos han representado un papel de vanguardia en el sentido de una definición más clara de la organización mundial que no toca sus tasas de desarrollo económico. Se ha dicho que si las Naciones Unidas han demostrado fallas y deficiencias en el campo del mantenimiento de la paz y de la seguridad internacional, sería injusto negar lo mucho que la organización mundial ha realizado en el campo económico y social.

Estamos muy lejos de participar de esa apreciación optimista. La verdad es que la Primera Década de Desarrollo fue un fracaso, pues al terminar ésta, los países ricos se habian vuelto más ricos y los países pobres se habían vuelto más pobres. El gap económico no hizo sino aumentar en los años que van de 1960 a 1970. Los progresos realizados en el ámbito de las Conferencias de la UNGTAD han sido bastante lentos y bastante modestos.

No negaremos que, a partir de 1964, cuando se trató de obtener, por primera vez, el reconocimiento de la íntima correlación entre los problemas del desarrollo económico y los problemas del comercio internacional, los países desarrollados presentaron algunos signos de una consideración más constructiva en relación a los problemas de los países subdesarrollados.

Lo que sucedió, entretanto, fue que esos problemas económicos 
se agravaron a un ritmo mucho más veloz que el que revela el cambio de actitudes, y el panorama económico mundial es todavía más sombrío que en 1964, en lo que concierne a las disparidades que persisten y tienden a acentuarse.

El programa de desarrollo económico de las Naciones Unidas es bastante modesto. Su presupuesto no va más allá de 250 millones de dólares, lo que es irrisorio si se toma en cuenta las proporciones gigantescas del programa a realizar y se atiende al hecho de que esa suma representa poco más de un milésimo de lo que el mundo consume anualmente en la carrera armamentista.

Este punto de desarrollo económico es uno de los que separan la actuación de los países latinoamericanos de la actuación de los EE. UU. en el ámbito de las Naciones Unidas y también en el ámbito de la Organización de Estados Americanos.

EI problema no es de fácil solución. Queremos traspasar a la esfera internacional ciertas ideas, concepciones y principios de justicia social y redistribución de riqueza, que fueron poco a poco ganando terreno dentro de las fronteras de cada uno de los estados miembros. Tenemos por delante un gran trabajo de persuasión y de convencimiento, que lleve a la opinión pública de los países altamente industrializados a aceptar los encargos financieros que resultarían en la concretización de una doctirna de seguridad colectiva en el campo económico, semejante a aquel que, con base muy precaria, tratamos de establecer en San Francisco, en el campo específico de la paz y la seguridad internacional. Estamos todavía muy lejos de la práctica e incluso de la teoría de un "impuesto a la renta internacional".

Todavía de manera incompleta e insuficiente, los EE.UU. han presentado una posición más flexible y más promisora que la de los países del bloque socialista, siendo éstos totalmente negativos en lo referente a los problemas de desarrollo en el plano mundial. Está partiendo precisamente de los paises socialistas la mayor oposición al proyecto de resolución latinoamericano que reclama medidas concretas y positivas en el contexto de la Segunda Década para el Desarrollo, destinadas a reducir y finalmente, a eliminar, la brecha económica entre los países en desarrollo y los países desarrollados.

Repetimos aquí lo que dijimos antes: en materia de cooperación económica internacional, los países socialistas están aferrados a conceptos de estricto y tacaño liberalismo económico. Los socialistas, en el escenario económico internacional, no quieren, de manera alguna, aceptar el principio de una atenuación de ciertas leyes económicas que contribuyen al deterioro de los terms of trade del comercio internacional.

Parece no repugnar a la conciencia de los países socialistas, algunos de los cuales deberían lógicamente formar filas al lado de los 
países en desarrollo si tuviesen libertad de acción para la defensa de sus intereses nacionales, la idea de que los países ricos se estén volviendo más ricos y los países pobres más pobres. En el campo internacional, no repugna a la Unión Soviética que la ley de acumulación de capitales continúe operando de la manera más libre y sin trabas. A ese respecto, alguien ya dijo que los delegados socialistas dejan en casa sus libros de Marx cada vez que comparecen al edificio de la Asamblea General.

En este asunto del desarrollo económico, los países latinoamericanos han procurado una acción común con los miembros del llamado grupo de los 77, también integrados por los países subdesarrollados de África y Asia. Está claro, entretanto, que los países latinoamericanos esperan de los EE.UU. iniciativas más amplias de cooperación económica en el plano internacional, mediante, inclusive, la eliminación de factores y circunstancias que impiden un acceso más libre de los productos de los países de América. Se trata de medidas esenciales para el fortalecimiento de la unidad americana y de toda la concepción del panamericanismo.

PROBLEMAS DE SEGURIDAD

Las fallas y deficiencias del sistema de seguridad de Naciones Unidas -que nunca llegó propiamente a organizarse- obligan a los países del hemisferio a medidas y providencias en el sentido de la defensa común y solidaria de sus condiciones de vida y seguridad. El Tratado Interamericano de Asistencia Recíproca firmado en Río de Janeiro, responde a esa preocupación fundamental. La aparición de nuevas formas insidiosas de agresión interna, consustanciada en actos de terrorismo, secuestro, atentados, guerrillas urbanas, etc., están entretanto reclamando medidas efectivas de cooperación entre los estados americanos, con vistas al mantenimiento de nuestra manera de vivir, en base a la igualdad, respeto mutuo y observancia de todos los principios del derecho internacional.

Sería inútil disfrazar las preocupaciones suscitadas por el presente estado de América Latina. Con tantos factores de inquietud y perturbación, nuevos instrumentos internacionales tendrán que enfrentar situaciones enteramente nuevas. Nuevos crímenes tendrán que ser conceptuados. $Y$ en un esfuerzo conjunto de cooperación, las naciones que componen la familia interamericana tendrán que hacer frente a la necesidad imperiosa de hacer respetar el principio de derecho internacional y de derecho positivo interamericano que veda 
la interferencia de un estado en asuntos de estricta jurisdicción interna de otro.

\author{
UNIDAD $Y$ DIVERSIDAD
}

Los países que integran el continente presentan las condiciones más diversas en materia de instituciones políticas, condiciones de vida y nivel económico y social. Existe en los EE.UU. la tendencia a tomar a América Latina en bloque, como si se tratase de un todo dotado de las mismas características políticas, económicas y culturales. Este es un terreno propicio para simplificaciones excesivas y generalizaciones apresuradas. Alguien llegó incluso a decir: "The americans will do anything for Latin America, except read about it". Y pravelece además la visión de Hollywood de los países latinoamericanos.

En realidad, no somos ni tan pintorescos ni tan livianos como inexplicablemente aparecemos en el mundo de la caricatura. Y debe decirse que estamos ante un continente entero, en un mundo que, a fin de cuentas, no posee más que cinco continentes. Por todos esos motivos, América Latina es un elemento importante en el libre juego de la política mundial, y es increíble la "cortina de silencio" que, en la prensa norteamericana, pesa sobre la vida y sobre las actividades de América Latina. Hechos de nuestra vida política son presentados bajo las peores formas de distorsión y de envenenamiento. Esos hechos y esta situación tienen que ser corregidos, si queremos, como debemos querer, alcanzar una mejor comprensión entre nosotros. Porque, a pesar de la diversidad de condiciones y peculiaridades locales, América está lejos de ser una abstracción. Representa una postura de libertad y soberanía frente a los problemas del mundo y una afirmación de la persona y de los derechos humanos frente a las doctrinas de opresión y tiranía que repetidamente nos están llegando del otro lado del Atlántico y ahora comienzan a venir del otro lado del Pacífico. Esa unidad, entretanto, no podrá ser impuesta por criterios y por métodos arbitrarios. Debe ser una unidad que presuponga una diversidad anterior que se disuelva en la comprensión y en el entendimiento mutuo y no una realidad ficticia e imaginaria, que no resistiría las condiciones de nuestro tiempo y apenas estimularía una tendencia hacia la inevitable diversificación. 


\section{CONCLUSIÓN}

No fue ciertamente nuestra intención dar un tratamiento formal y sistemático a este tema de la problemática mundial y de la posición del continente americano dentro de esa misma problemática. Nos limitamos a trazar un cuadro de carácter muy general, a ofrecer antes una tabulación de temas para el desarrollo posterior que un puñado de opiniones y puntos de vista sobre los problemas políticos de actualidad.

En materia tan fluida y tan imprecisa, cualquier dogmatismo sería imposible y de cualquier manera, escaparía enteramente a la realidad. Es posible que las computadoras se revelen más eficientes en el futuro. Los hombres todavía no aprendieron a prever el curso de la historia, tal vez porque participan de ella.

Lo máximo que podemos hacer es identificar ciertos hechos $y$ ciertas tendencias que, de persistir y afirmarse, podrán producir tales o cuales resultados. Pero la historia siempre escogió su propio camino, independiente de las previsiones humanas. 